Please do not remove this page

RMIT

UNIVERSITY

\title{
Increased nitric oxide activity compensates for increased oxidative stress to maintain endothelial function in rat aorta in early type 1 diabetes
}

Joshi, A; Woodman, Owen

https://researchrepository.rmit.edu.au/esploro/outputs/9921859407301341/filesAndLinks?institution=61RMIT_INST\&index=null

Joshi, A., \& Woodman, O. (2012). Increased nitric oxide activity compensates for increased oxidative stress to maintain endothelial function in rat aorta in early type 1 diabetes. Naunyn-Schmiedeberg's Archives of Pharmacology, 385(11), 1083-1094. https://doi.org/10.1007/s00210-012-0794-3

Document Version: Accepted Manuscript

Published Version: https://doi.org/10.1007/s00210-012-0794-3

Repository homepage: https://researchrepository.rmit.edu.au

(c) 2012 Springer-Verlag.

Downloaded On 2023/04/26 21:57:01 +1000

Please do not remove this page 
Thank you for downloading this document from the RMIT Research Repository.

The RMIT Research Repository is an open access database showcasing the research outputs of RMIT University researchers.

RMIT Research Repository: http://researchbank.rmit.edu.au/

\section{Citation:}

Joshi, A and Woodman, O 2012, 'Increased nitric oxide activity compensates for increased oxidative stress to maintain endothelial function in rat aorta in early type 1 diabetes', Naunyn-Schmiedeberg's Archives of Pharmacology, vol. 385, no. 11, pp. 1083-1094.

See this record in the RMIT Research Repository at:

http://researchbank.rmit.edu.au/view/rmit:20564

Version: Accepted Manuscript

Copyright Statement: (c) 2012 Springer-Verlag.

Link to Published Version:

http://dx.doi.org/10.1007/s00210-012-0794-3 
INCREASED NITRIC OXIDE ACTIVITY COMPENSATES FOR INCREASED

\title{
OXIDATIVE STRESS TO MAINTAIN ENDOTHELIAL FUNCTION IN RAT AORTA IN
}

\section{EARLY TYPE 1 DIABETES}

\author{
A.Joshi ${ }^{1}$ and O.L. Woodman ${ }^{1,2^{*}}$ \\ ${ }^{1}$ Department of Pharmacology, University of Melbourne, Victoria, Australia. \\ Email: anjali.jo@gmail.com \\ ${ }^{2}$ School of Medical Sciences, RMIT University, Bundoora, Victoria, Australia. \\ Email: owen.woodman@rmit.edu.au
}

*Correspondence:

Professor Owen Woodman

School of Medical Sciences

RMIT University

PO Box 71 Bundoora

Victoria 3083 Australia

Tel: +61(03) 99257305

Fax: +61(03) 99257063

Email: owen.woodman@rmit.edu.au 
RUNNING TITLE: Oxidative stress in diabetic endothelial dysfunction

\section{ABSTRACT}

Purpose: Hyperglycaemia and oxidative stress are known to acutely cause endothelial dysfunction in vitro, but in the initial stages of diabetes endothelium-dependent relaxation is preserved. The aim of this study was to investigate how endothelium-dependent relaxation is maintained in the early stages of type-1 diabetes.

Methods: Diabetes was induced in Sprague-Dawley rats with a single injection of streptozocin (48 $\mathrm{mg} / \mathrm{kg}$, i.v.) and after 6 weeks endothelium-dependent and -independent relaxation was examined in the thoracic aorta in vitro. Lucigenin-enhanced chemiluminescence was used to measure superoxide generation from the aorta.

Results: Diabetes increased superoxide generation by the aorta (2180 \pm 363 vs $986 \pm 163$ AU/mg dry tissue weight). ACh-induced relaxation was similar in aortae from control ( $\mathrm{pEC}_{50}$ 7.36 $\pm 0.09, \mathrm{R}_{\max }$ $95 \pm 3 \%$ ) and diabetic rats ( $\mathrm{pEC}_{50} 7.33 \pm 0.10 \mathrm{R}_{\max } 88 \pm 5 \%$ ). The ACh-induced relaxation was abolished by the combined presence of the NOS inhibitor L-NNA $(100 \mu \mathrm{M})$ and an inhibitor of soluble guanylate cyclase, ODQ $(10 \mu \mathrm{M})$ in control rats but under the same conditions the diabetic aortic rings showed significant relaxation to ACh ( $\mathrm{pEC}_{50} 6.75 \pm 0.15, \mathrm{R}_{\max } 25 \pm 4 \%$, $\mathrm{p}<0.05$ ). In diabetic aortae the addition of haemoglobin, which inactivates nitric oxide, to L-NNA+ODQ abolished the response to ACh. The addition of the potassium channel blockers, apamin and TRAM-34 to L-NNA+ODQ also abolished the relaxation response to ACh. Diabetes significantly elevated plasma total nitrite/nitrate and increased expression of eNOS and calmodulin in aortae.

Conclusions: These data indicate that after 6 weeks of diabetes, despite increased oxidant stress, endothelium-dependent relaxation is maintained due to the increased eNOS expression resulting in increased NO synthesis. In diabetic arteries NO acts both through, and independently of, cGMP pathways to cause relaxation. 


\section{KEY WORDS:}

Diabetes, endothelium derived hyperpolarising factor, endothelium, nitric oxide, nitrosothiols, potassium channels. 


\section{INTRODUCTION}

Cardiovascular complications are the major cause of morbidity and mortality in diabetic patients (Lopes-Virella et al., 2008). The pathogenic role of glucose in cardiovascular disease is increasingly apparent, as confirmed by studies carried out both on diabetic and non-diabetic patients (Bartnik et al., 2007). Acute hyperglycaemia (3-6 hrs) induces endothelial dysfunction of the aorta as well as of the renal circulation of non-diabetic rabbits (Gomes et al., 2004) and numerous studies report that long-term hyperglycaemia leads to endothelial dysfunction in various animal models of diabetes (Pieper et al., 1998, Pieper, 1999, Csanyi et al., 2007) and in humans (Johnstone et al., 1993). Hyperglycaemia both acute (Goel et al., 2007) and chronic (Karasu, 2000) is known to induce oxidative stress and it has been proposed that oxidative stress leads to endothelial dysfunction (Ammar et al., 2000, Hink et al., 2001, Jay et al., 2006). It is surprising then to note that there are several reports that endothelial function is normal after a short duration (2-4 weeks) of diabetes despite the presence of hyperglycaemia (Orie et al., 1993, Pieper, 1999, Shen et al., 2003).

Pieper (1999) reported a triphasic effect of diabetes on endothelial function. Initially endotheliumdependent relaxation was increased after 1 week of diabetes followed by a normal response after 2 weeks and impaired response after 8 weeks of diabetes. While the mechanism of endothelial dysfunction has been extensively studied in long-term diabetes, it still remains to be elucidated how endothelium-dependent relaxation is maintained in the early stages of type-1 diabetes.

The endothelium produces vasodilators such as nitric oxide, prostacyclin and a still unidentified, endothelium-derived hyperpolarising factor (EDHF) (Bryan et al., 2005). Nitric oxide is considered to be the main endothelium-derived relaxing factor in larger arteries (Clark and Fuchs, 1997). The major source of nitric oxide in the endothelium is endothelial nitric oxide synthase (eNOS) but a small amount of nitric oxide may also be released from preformed endothelial nitrosothiol stores (Alencar et al., 2003, Lima et al., 2010). 
There are several possible mechanisms that may contribute to the maintenance of endothelial function in short-term diabetes e.g. increased production of nitric oxide (Stadler et al., 2003), increased expression of eNOS (Hink et al., 2001) or a compensatory upregulation of the release other vasodilators (Shi et al., 2006, Malakul et al., 2008, Nacci et al., 2009). Several studies have shown increased nitric oxide production in the early stages of diabetes. Stadler et al. (2003) reported increased production of nitric oxide in aortae from diabetic rats for a limited time after induction of diabetes (up to 7 weeks). There are conflicting reports regarding expression of eNOS at various stages of diabetes. Hink et al. (2001) showed an increased expression of eNOS but decreased basal nitric oxide in aortae after 2 weeks of diabetes leading the authors to propose that eNOS became uncoupled and shift towards superoxide rather than nitric oxide synthesis whereas Bojunga et al. (2004) reported a decreased expression of eNOS in diabetic aorta but increased production of nitric oxide. On the other hand, increased expression of inducible NOS has also been demonstrated in diabetic rat aorta and heart (Bojunga et al., 2004, Jesmin et al., 2006). Overall it has been demonstrated that whereas diabetes induces endothelial dysfunction by decreased synthesis or increased breakdown of nitric oxide (Beckman and Crow, 1993, Jay et al., 2006) in the longer term but it is yet not clear what changes take place in early diabetes to maintain endothelial function despite hyperglycaemia and oxidant stress.

As there has been limited investigation of the the mechanism of relaxation in early diabetes (Shen et al., 2003, Abboud et al., 2009) the purpose of this study was to gain better understanding of mechanism of endothelium-dependent relaxation in the early stages of type-1 diabetes before acetylcholine-induced relaxation is impaired with a focus on the determination of the role of various endothelium-derived vasodilators in maintaining endothelial function in the presence of increased oxidative stress. 


\section{METHODS}

\section{Animals}

Male Sprague-Dawley rats (200-230 g, 8 weeks, Animal Resource Centre, Perth, WA) were housed 2-3 per cage, fed standard rat chow and had free access to food and water. All the experiments were performed according to the guidelines of the National Health and Medical Research Council of Australia and approved by the Animal Ethics Committees of the University of Melbourne and RMIT University.

\section{Induction of diabetes}

Diabetes was induced in rats by a single injection of streptozotocin (48 mg/kg) dissolved in $0.1 \mathrm{M}$ citrate buffer ( $\mathrm{pH} 4.5$ ) into the tail vein after an overnight fast. Control rats received an injection of citrate buffer. Blood glucose was measured at the time of experiment for all groups using an AccuCheck Advantage II monitor (Roche, Mannheim, Germany). The rats showing blood glucose of $>20$ $\mathrm{mmol} / \mathrm{L}$ were considered to be diabetic.

\section{Preparation of aortic rings}

The rats were killed 6 weeks after streptozotocin or vehicle injection by exposure to a mixture of halothane and oxygen for $5 \mathrm{~min}$. The chest was opened and the thoracic aorta was isolated. After removing superficial fat and connective tissue, the thoracic aorta was cut into 2-3 mm long rings and mounted in organ baths in Krebs bicarbonate solution (118 mM NaCl, $4.7 \mathrm{mM} \mathrm{KCl,} 1.18 \mathrm{mM}$ $\mathrm{MgSO}_{4}, 1.2 \mathrm{mM} \mathrm{KH}_{2} \mathrm{PO}_{4}, 25 \mathrm{mM} \mathrm{NaHCO}_{3}, 11.1 \mathrm{mM}$ D-glucose, and $1.6 \mathrm{mM} \mathrm{CaCl}_{2}$ ), bubbled with $5 \% \mathrm{CO}_{2}$ in $\mathrm{O}_{2}$ at $37^{\circ} \mathrm{C}$ to assess vascular function. Blood plasma was collected for $\mathrm{NOx}$ assay and from some of the rats, the thoracic aorta was isolated and immediately frozen for western blotting. 


\section{Functional experiments}

The aortic rings, mounted in organ baths at a resting tension of 1g, were equilibrated for 60-90 min with the bath medium changed every $15 \mathrm{~min}$. The tissues were maximally contracted by exposure to physiological saline solution containing a high potassium concentration of $123 \mathrm{mM}$. Endothelial integrity was determined by measuring the relaxation caused by exposure to acetylcholine $\left(10^{-5} \mathrm{M}\right)$ in phenylephrine-precontracted rings and the endothelium was considered to be intact if the preparation relaxed by greater than $80 \%$. Cumulative concentration response curves to acetylcholine and sodium nitroprusside were determined using rings submaximally contracted with phenylephrine $\left(10^{-8}\right.$ to $\left.10^{-7} \mathrm{M}\right)$. Responses to acetylcholine and sodium nitroprusside were also tested in the presence or absence of N-nitro-L-arginine (L-NNA, $100 \mu \mathrm{M}$ ) a nitric oxide synthase (NOS) inhibitor, $1 \mathrm{H}-[1,2,4]$ oxadiazolo[4,3-a]quinoxalin-1-one (ODQ, $10 \mu \mathrm{M})$ a soluble guanylate cylase (sGC) inhibitor , indomethacin $(10 \mu \mathrm{M})$ a cyclooxygenase inhibitor, apamin $(1 \mu \mathrm{M})$ a small conductance calcium activated potassium channel $\left(\mathrm{SK}_{\mathrm{Ca}}\right)$ blocker , TRAM-34 $(1 \mu \mathrm{M})$ an intermediate conductance calcium activated potassium channel $\left(\mathrm{IK}_{\mathrm{Ca}}\right)$ blocker, haemoglobin (20 $\mu \mathrm{M})$ a nitric oxide scavenger , carboxy-PTIO (20 mM) a scavenger of NO` and L-cysteine (1 mM) a scavenger of NO.

\section{Lucigenin-enhanced chemiluminescence assay}

Lucigenin-enhanced chemiluminescence was used to measure superoxide release from aortic rings that were not used in the functional experiments, using a previously described procedure (Chan et al., 2003). At the conclusion of the assay, tissues were dried for $48 \mathrm{~h}$ at $65^{\circ} \mathrm{C}$ to allow superoxide production to be normalized to dry tissue weight. The results were expressed as superoxide counts per mg tissue.

\section{Western blot analysis}

Western blots were performed as described previously (Woodman et al., 2004) with the following modifications. The aortic tissues were homogenized and the total protein concentration of the 
samples was quantified using a Bradford assay. Equal amounts of protein homogenate were subjected to SDS-PAGE and western blot analysis with mouse antibodies against eNOS, inducibleNOS, caveolin-1 (Transduction Laboratories), calmodulin (Millipore), NADPH oxidase (NOX)-2 and heme oxygenase-1 (AbCAM). To normalize for the amount of protein loaded on the gels, membranes were reprobed with a loading control antibody ( $\beta$-tubulin, AbCAM). All proteins were detected by enchanced chemiluminescence (Amersham) after incubation with anti-mouse secondary antibody. All protein bands were quantified by densitometry (Biorad Chemidoc) and expressed as a ratio of the loading control.

\section{Nitrite estimation}

The level of nitric oxide metabolites (NOx, ie. nitrite + nitrate) was measured in plasma using a colorimetric assay kit (Roche Diagnostics). Plasma samples were stored at $-80^{\circ} \mathrm{C}$ until assayed. The concentration of $\mathrm{NO}_{\mathrm{x}}$ was measured in samples of plasma after converting all nitrates to nitrite with nitrate reductase. Total nitrite levels were measured in duplicate by absorbance at $560 \mathrm{~nm}$ using the Griess reaction. The calibration curve was prepared using sodium nitrite as a standard.

\section{Drugs}

Acetylcholine perchlorate (BDH Chemicals), apamin (Sigma), L-cysteine (Sigma), phydroxymercuribenzoic acid (Sigma) and phenylephrine hydrochloride (Sigma) were all dissolved in distilled water. Haemoglobin (Sigma) and sodium nitroprusside (Sigma) were dissolved in Krebs solution. Indomethacin (Sigma) was dissolved in 0.1M sodium carbonate and L-NNA (Sigma) was dissolved in 0.1 M sodium bicarbonate. Ethacrynic acid (Sigma), ODQ (Cayman), carboxy-PTIO (Cayman) and TRAM-34 (Sigma) were dissolved in dimethyl sulfoxide. The final concentrations of DMSO in the bath were $0.0001 \%-0.01 \%$ while performing the functional experiments which has been shown to have no effect on vasorelaxation in these concentrations. 


\section{Analysis and statistics}

Concentration-response data were fitted to a sigmoidal plot using GraphPad Prism version 5.0, which estimated the $\mathrm{pEC}_{50}$. Statistical analysis was carried out using Student's unpaired t-test or multiple comparisons were performed using analysis of variance (ANOVA) followed by a Bonferroni post test. $\mathrm{p}<0.05$ was considered statistically significant. All values are presented as mean \pm SEM. Each n represents the number of animals per group. 


\section{RESULTS}

\section{Blood glucose and body weight}

The control and diabetic animals had a similar initial body weight but diabetic animals had a significantly lower body weight at the end of 6 weeks compared to control animals (Table 1). All of the diabetic animals exhibited hyperglycaemia at the time of experiment.

\section{Vascular superoxide}

Superoxide counts measured from segments of thoracic aorta were significantly higher in diabetic animals compared to control animals using the lucigenin-enhanced chemiluminescence assay. Diphenyliodonium, a non-selective inhibitor of NADPH oxidase, reduced the amount of superoxide generation in both groups (Table 1).

\section{Plasma nitrite concentrations}

The diabetic animals showed significantly higher plasma $\mathrm{NO}_{\mathrm{x}}$ concentration compared to control animals (Table 1).

\section{Endothelium-dependent and endothelium-independent relaxation}

6 weeks after streptozotocin injection, endothelium-dependent and endothelium-independent relaxation to acetylcholine $\left(10^{-10}\right.$ to $\left.10^{-5} \mathrm{M}\right)$ and sodium nitroprusside $\left(10^{-11}\right.$ to $\left.10^{-5} \mathrm{M}\right)$ respectively were similar in aortae from control and diabetic animals (Figure 1).

\section{Effect of L-NNA, ODQ and indomethacin on relaxation}

The presence of L-NNA or ODQ completely abolished acetylcholine-induced relaxation in control aortae (Figure 2). In the aortic rings from diabetic animals the relaxation was partially inhibited, but not abolished, by L-NNA or ODQ (Figure 2b). Pretreatment with indomethacin had no effect on relaxation to either ACh or SNP in normal or diabetic animals (Figure 2). The diabetic animals showed a higher sensitivity to the nitric oxide donor sodium nitroprusside in the presence of LNNA and ODQ compared to control animals. 


\section{Effect of nitric oxide scavengers on relaxation}

The presence of the nitric oxide scavenger haemoglobin in addition to L-NNA+ODQ abolished the relaxation response to acetylcholine in diabetic aortae (Figure 3a). The presence of haemoglobin significantly decreased the $\mathrm{pEC}_{50}$ to sodium nitroprusside in control as well as diabetic aortae. Carboxy-PTIO and L-cysteine also significantly decreased the $\mathrm{pEC}_{50}$ and $\mathrm{R}_{\max }$ to acetylcholine in diabetic aorta when used in combination with L-NNA (Figure 3). The $\mathrm{pEC}_{50}$ and $\mathrm{R}_{\max }$ values for acetylcholine and sodium nitroprusside in the presence of these inhibitors are shown in Tables 2 and

3.

\section{Effect on relaxation of agents depleting nitrosothiol stores}

The role of preformed nitrosothiol stores in relaxation response to acetylcholine in diabetic aorta was examined using nitrosothiol depleting agent ethacrynic acid (EA) and phydroxymercuribenzoic acid (PHMBA). The aortic rings were incubated for 20 minutes with LNNA with or without ethacrynic acid or PHMBA. After the first exposure of acetylcholine, the rings incubated with ethacrynic acid or PHMBA showed significantly less relaxation compared to L-NNA incubated rings (Figure 4). After the second exposure to acetlycholine, the ethacrynic acid and PHMBA incubated rings showed contraction indicating a complete depletion of nitrosothiol stores.

\section{Effect of potassium channel blockers on relaxation}

The presence of apamin plus Tram-34 had no effect on vasorelaxation to acetylcholine or to sodium nitroprusside in control aortae (Figure 2c) whereas in diabetic animals they significantly decreased the maximum relaxation to acetylcholine (Figure 2d) but had no effect on sodium nitroprusside responses (Table 3). In diabetic animals the relaxation to acetylcholine observed in the presence of ODQ plus L-NNA was abolished by addition of apamin and TRAM-34 (Figure 2d) and the maximum response to sodium nitroprusside was significantly decreased compared to control aortae (Table 3). 


\section{Protein expression by western blot analysis}

The expression of eNOS, calmodulin and NADPH oxidase- 2 was found to be significantly increased in aortae from the diabetic group compared to control (Figure 5). The eNOS dimermonomer ratio was significantly decreased in diabetic aorta. The expression of caveolin and heme oxygenase-1 was not altered by diabetes. Inducible NOS expression was not detected in either of the groups (data not shown). 


\section{DISCUSSION}

Our study showed that, despite an increase in oxidative stress, endothelium-dependent and endothelium-independent relaxation of the rat aorta was unaltered in the early stages of diabetes, but the mechanism of endothelium-dependent relaxation had been changed. We found that endothelium-dependent relaxation of diabetic aortae was resistant to inhibition by a NOS inhibitor and/or inhibition of sGC and that the remaining component of relaxation was sensitive to $\mathrm{SK}_{\mathrm{Ca}}$ and $\mathrm{IK}_{\mathrm{Ca}}$ channel blockers as well as nitric oxide scavengers. In diabetic arteries the nitrosothiol depleting agents also abolished the relaxation response to acetylcholine that persisted in the presence of L-NNA. Western blot analysis showed increased expression of eNOS and calmodulin in diabetic aortae, which may explain the increase in nitric oxide synthesis, indicated by the elevation in plasma nitrite levels. These results suggest that despite increased oxidative stress, endothelial function was maintained in early diabetes due to a compensatory increased activity of nitric oxide which acted primarily through activating soluble guanylate cyclase and partly through the opening of potassium channels. In diabetes, nitrosothiol stores acted as the additional source of nitric oxide in addition to eNOS.

Hyperglycaemia increases superoxide production by several mechanisms, including autooxidation of glucose, activation of polyol pathways, and generation of advanced glycation end products (Jay et al., 2006). Several enzymes are involved in the production of ROS at a vascular level such as cyclooxygenase, NADPH oxidase and xanthine oxidase (Ellis and Triggle, 2003). In vascular disease, uncoupling of NOS also accounts for the increased ROS production. In this study diabetic animals showed an increase in oxidative stress measured by production of superoxide counts using lucigenin-enhanced chemiluminescence. We also found increased expression of NADPH oxidase -2 in diabetic rat aorta compared to control animals (Figure 5). Diphenyliodonium, a non-selective inhibitor of NADPH oxidase enzyme, blocked the production of superoxide in lucigenin assay (Table 1) suggesting that NADPH oxidase is the major source of superoxide. The dimer-monomer ratio of eNOS was decreased in diabetic animals (Figure 5) suggesting eNOS was 
uncoupled form and therefore may also contribute to superoxide production. These results are consistent with other studies which have shown increased oxidative stress (Bitar et al., 2005, Ding et al., 2007) as well as increased activity/expression of NADPH oxidase, p22 phox and p67phox subunits in diabetes (Wendt et al., 2005, Guo et al., 2007).

Hyperglycaemia, both acute and chronic, has been widely reported to cause endothelial dysfunction. Rat aortic rings showed a diminished response to endothelium-dependent vasodilator when incubated with high glucose for 2-6 hrs (Gomes et al., 2004, Goel et al., 2007, Fang et al., 2009). By contrast, diabetic animals have shown variable endothelium-dependent relaxation responses depending upon the duration of diabetes (Pieper, 1999). In the early stages of diabetes (16 weeks of induction), it has been reported that endothelium-dependent relaxation is unaltered (Orie et al., 1993, Garcia et al., 1999) or increased in rats (Altan et al., 1989) or mice (Shen et al., 2003). By contrast, there are numerous studies which have reported decreased relaxation responses in various animal models of long-term diabetes (8 weeks or more) (Oyama et al., 1986, Garcia-Pascual et al., 1995, Bitar et al., 2005, Alper et al., 2006). Whilst the mechanism of endothelial dysfunction has been widely explored in long-term diabetes, it is yet to be established why endotheliumdependent relaxation is either unchanged or increased in early diabetes.

In aortae, the endothelium-dependent relaxation is normally mediated entirely by nitric oxide through the activation of sGC (Clark and Fuchs, 1997). This was confirmed by complete blockade of acetylcholine-induced relaxation by the NOS inhibitor, L-NNA or the sGC inhibitor ODQ in control animals. By contrast, aortae from the diabetic animals showed significant relaxation in the presence of L-NNA, ODQ or the combination of both. We postulated that this might be due to increased nitric oxide activity or that there might be a compensatory up-regulation of another non-nitric oxide pathway of relaxation. We investigated the possibility of increased nitric oxide activity by using nitric oxide scavengers, in combination with L-NNA and ODQ. The L-NNA and ODQ resistant relaxation to acetylcholine was found to be sensitive to haemoglobin (Figure 3a) and was also significantly decreased by L-cysteine, a scavenger of $\mathrm{NO}^{-}$or carboxy-PTIO (scavenger of 
NO ), suggesting an increased nitric oxide activity in diabetes as well as advocating potential contribution of both $\mathrm{NO}$ and $\mathrm{NO}^{-}$in acetylcholine-induced relaxation in diabetes. Haemoglobin has also been shown to bind nitrosothiol (Kim-Shapiro et al., 2006) and previous studies have shown that pre-formed stores of nitric oxide could exist in vascular tissue in the form of nitrosothiols and nitric oxide in the form of $\mathrm{NO}^{*} / \mathrm{NO}^{-}$could be released from these stores by acetylcholine even in the presence of a NOS inhibitor (Ng et al., 2007). Nitrosothiol-derived compounds have been suggested to be potent vasodilators (Myers et al., 1990, Bates et al., 1991) which may cause relaxation mediated by both sGC and the opening of SK $\mathrm{Ca}_{\mathrm{a}}$ and $\mathrm{IK}_{\mathrm{Ca}}$ channels (Batenburg et al., 2009) and recent reports suggest a physiological role for $\mathrm{NO}^{-}$in spreading vasodilation (Yuill et al., 2011). It is also interesting to note that vasorelaxant responses to nitroxyl donors are maintained in the presence of oxidant stress (Bullen et al., 2011) supporting the possibility that $\mathrm{NO}^{`}$ might contribute to relaxation in diabetes. Our results using nitrosothiol depleting agents (Figure 4) also support a contribution of nitric oxide released from pre-formed nitrosothiol stores towards endotheliumdependent relaxation in early diabetes. This is consistent with the observations of $\mathrm{Ng}$ et al. (2007) who found concluded that relaxation caused by ultraviolet light involved release of pre-formed NO stores that was unaffected by type 2 diabetes.

In our study diabetic animals showed a significant increase in total plasma nitrite/nitrate levels (Table 1) consistent with earlier reports that demonstrated increased nitrite levels in short term (4 weeks) diabetes (Bojunga et al., 2004). Stadler et al. (2003) found increased nitric oxide levels in diabetic aorta starting from 2 weeks up to 7 weeks after diabetes induction. We also observed increased expression of eNOS protein in diabetic aorta (Figure 5) but inducible NOS was not detected. Several studies in diabetes had reported an upregulated, but dysfunctional, uncoupled NOS leading to increased oxidative stress and endothelial dysfunction (Hink et al., 2001, Satoh et al., 2005) and we also found a lower expression for the eNOS dimer and higher expression for the eNOS monomer indicating uncoupling and the potential to generate superoxide rather than nitric oxide. A further possibility is that in the presence of elevated oxidant stress the consequent 
depletion of $\mathrm{BH}_{4}$ could promote the synthesis of $\mathrm{NO}^{-}$rather than NO by eNOS as previously reported (Rusche et al., 1998, Adak et al., 2000). We also investigated expression of two proteins that modulate eNOS activity (i.e. calmodulin and caveolin-1). The constitutively expressed eNOS is catalytically inactive when bound to caveolin-1, however, calmodulin displaces caveolin-1 in the presence of calcium and binds to eNOS and thereby activates eNOS to produce nitric oxide (Frank et al., 2007) . We found that the expression of calmodulin was significantly increased while expression of caveolin-1 remained unchanged in diabetes. Takahashi and Mendelsohn (2003) reported that calmodulin causes concentration dependent increases in eNOS activity in vitro and we, and others, have reported that an increase in calmodulin expression in vivo is associated with an increase in eNOS activity (Sobey et al., 2004, Woodman et al. 2004, Vera et al., 2007). This suggested that eNOS activity may be increased due to increased calmodulin binding despite a decreased dimer formation in diabetic aorta. Therefore, diabetic animals may produce more nitric oxide due to increased eNOS activity, to resist endothelial dysfunction caused by increased oxidative stress. There have been conflicting findings regarding eNOS regulation in diabetic animals with reports of both an increased (Stockklauser-Färber et al., 2000) or decreased (Komers et al., 2006) expression. Stockklauser-Färber et al. (2000) found that initially cardiac NOS expression and activity increased to a maximum after 4-6 weeks of diabetes and then decreased afterwards. They suggested that high glucose could lead to induction of eNOS in the early stages of diabetes in response to increased ROS production as the increase in eNOS could be blocked by antioxidant treatment. In a recent study, Riad et al. (2008) found a marked decrease in eNOS expression in diabetic skeletal muscle after 8 weeks of streptozotocin injection and stimulation of eNOS production by eNOS transcription enhancer AVE3085 improved endothelial function and reduced oxidative stress and vascular inflammatory responses. Taken together, our results suggested a compensatory increase in basal nitric oxide levels to combat increased oxidative stress in diabetic aorta. 
The endothelial SK $\mathrm{Ca}_{\mathrm{C}}$ and $\mathrm{IK}_{\mathrm{Ca}}$ channels have been reported to contribute to ACh-induced endothelial hyperpolarization and NO-mediated relaxation in large arteries (Stankevicius et al., 2006). It is also reported that opening of $\mathrm{SK}_{\mathrm{Ca}}$ and $\mathrm{IK}_{\mathrm{Ca}}$ channels decreases myogenic tone and increases ACh-induced relaxation in rat cremaster arterioles (Sheng et al., 2009) and restores attenuated EDHF-type relaxation in mesenteric small arteries from Zucker diabetic fatty rats (Brondum et al., 2010). Also recent studies have suggested that $\mathrm{SK}_{\mathrm{Ca}}$ and $\mathrm{IK}_{\mathrm{Ca}}$ channel opening is associated with the activation of NO synthase and NO production (Stankevicius et al., 2006, Sheng and Braun, 2007, Brahler et al., 2009, Sheng et al., 2009, Dalsgaard et al., 2010). The production of endothelium-dependent relaxing factors generally involves an increase in the intracellular $\mathrm{Ca}^{2+}$

concentration $\left[\mathrm{Ca}^{2+}\right]$ i. An increase in endothelial $\left[\mathrm{Ca}^{2+}\right]$ i will open calcium-activated potassium channels of small $\left(\mathrm{SK}_{\mathrm{Ca}}\right)$ and intermediate $\left(\mathrm{IK}_{\mathrm{Ca}}\right)$ conductance, thereby hyperpolarizing the endothelial cell. A recent study showed that the SK $\mathrm{Ca}_{\mathrm{a}}$ and $\mathrm{IK}_{\mathrm{Ca}}$ channel opener NS309-induced calcium influx that contributed to the formation of NO (Stankevicius et al., 2011). However, further studies are required to clarify how activation of these mechanisms is coupled to increased formation of NO in endothelial cells.

\section{CONCLUSION}

Previous studies have suggested that even acute hyperglycaemia (Bartnik et al., 2007, Cameron and Cruickshank, 2007) or long term diabetes i.e. 8 weeks or more (Hink et al., 2001, Peredo et al., 2006) could lead to endothelial dysfunction due to increased oxidative stress and decreased nitric oxide bioavailability. We suggest that, in diabetes, an initial increased synthesis of nitric oxide by increased activity of eNOS might be able to compensate for increased oxidative stress leading to preserved endothelial function at the start of diabetes followed by a final reduction in endothelium response as the disease progresses leading to endothelial dysfunction. In the light of these findings, we can conclude that despite marked hyperglycaemia and increased oxidative stress, endothelium-dependent and -independent relaxation was maintained after 6 weeks of streptozotocin-induced diabetes due to increased nitric oxide bioavailability. The increase in nitric 
oxide bioavailability could be attributed to increased expression of eNOS and calmodulin and/or release from nitrosothiol stores. The nitric oxide could be acting through sGC as well as a sGCindependent pathway through activation of $\mathrm{SK}_{\mathrm{Ca}}$ and $\mathrm{IK}_{\mathrm{Ca}}$ channels to cause relaxation in diabetic rat aorta. Therefore our results suggest that increased nitric oxide bioavailability is a compensatory mechanism to counteract increased oxidative stress in the early stages of diabetes to maintain endothelial function in aorta.

\section{ABBREVIATIONS:}

EDHF, endothelium-derived hyperpolarising factor; eNOS, endothelial nitric oxide synthase; sGC, soluble guanylate cyclase; ODQ, 1H-(1,2,4)-oxadiazolo(4,2-a)quinoxalin-1-one; L-NNA, N-nitroL-arginine; TRAM-34, 1-[(2-chlorophenyl)(diphenyl)methyl]-1H-pyrazole;; IK Ca $_{\text {, intermediate- }}$ conductance calcium activated potassium channel; $\mathrm{SK}_{\mathrm{Ca}}$, small-conductance calcium-activated potassium channel; ROS, reactive oxygen species; PHMBA, p-hydroxymercuribenzoic acid.

\section{COMPETING INTEREST}

The authors declare that they do not have any competing interests.

\section{AUTHORS’ CONTRIBUTIONS}

AJ made substantial contributions to conception and design of experiments, performed the experiments, analysed the data and wrote the manuscript. OLW made substantial contributions to conception and design of experiments, edited the manuscript and contributed to the discussion. All authors read and approved the final manuscript. 


\section{ACKNOWLEDGMENTS}

The author would like to acknowledge the help from Mr C.H Leo during the course of study. Anjali Joshi was supported by a Melbourne University International Research Scholarship. 


\section{LEGENDS FOR FIGURES:}

Figure 1: Effect of 6 weeks of diabetes on endothelium-dependent and endothelium-independent relaxation responses to (a) acetylcholine $\left(10^{-10}\right.$ to $\left.10^{-5} \mathrm{M}\right)$ and (b) sodium nitroprusside (10 ${ }^{-11}$ to $10^{-5}$ $\mathrm{M})$ in phenylephrine $\left(10^{-8}\right.$ to $\left.10^{-7} \mathrm{M}\right)$ precontracted aortic rings. The data is expressed as mean \pm SEM. The $\mathrm{pEC}_{50}$ and $\mathrm{R}_{\max }$ values calculated from the data are shown in Table 2.

Figure 2: Concentration response curve to ACh in a) control b) diabetic animals in the presence of $(\bullet)$ vehicle, $(\bullet)$ N-nitro-L-arginine (L-NNA), ( $\square)$ ODQ, $(\Delta)$ indomethacin and c) control d) diabetic animals in the presence of $(\bullet)$ vehicle, $(\diamond)$ L-NNA+ODQ, (ø) Apamin+TRAM-34, $(\nabla)$ LNNA+ODQ+Apamin+TRAM-34 in phenylephrine $\left(10^{-8}\right.$ to $\left.10^{-7} \mathrm{M}\right)$ preconstricted aortic rings. The data is expressed as mean $\pm S E M$. The $\mathrm{pEC}_{50}$ and $\mathrm{R}_{\max }$ values calculated from the data are given in Tables 2 and 3.

Figure 3: Concentration response curve to acetylcholine (ACh) in diabetic animals in the presence of a) $(\bullet)$ vehicle, $(\diamond)$ L-NNA+ ODQ, $(\diamond) \mathrm{Hb}+\mathrm{ODQ},(\square) \mathrm{Hb}+\mathrm{L}-\mathrm{NNA}+\mathrm{ODQ}$ and b) $(\bullet)$ vehicle, $(\diamond)$ L-NNA, ( $\square$ ) L-NNA+carboxy-PTIO, ( $\Delta$ ) L-NNA+L-cysteine in phenylephrine $\left(10^{-8}\right.$ to $\left.10^{-7} \mathrm{M}\right)$ preconstricted aortic rings. All the experiments were performed in the presence of indomethacin. The data is expressed as mean $\pm \mathrm{SEM}$. The $\mathrm{pEC}_{50}$ and $\mathrm{R}_{\max }$ values calculated from the data is given in Tables 3 and 4.

Figure 4: Effect of the nitrosothiol depleting agents ethacrynic acid $(50 \mu \mathrm{M})$ and phydroxymercuribenzoic acid $(10 \mu \mathrm{M})$ on relaxation responses to three consecutive exposures to ACh $(10 \mu \mathrm{M})$ in the presence of L-NNA $(100 \mu \mathrm{M})$. All experiments were performed in the presence 
of indomethacin $(10 \mu \mathrm{M})$. * Significantly different compared to L-NNA treated rings (one way ANOVA, Bonferroni post test, $\mathrm{p}<0.05)$. $\mathrm{n}=4$ for each data set.

Figure 5: Protein expression of (a) eNOS, (b) calmodulin (c) NOX2 and (d) eNOS dimer-monomer in the normal and diabetic rat aorta determined by Western blot analysis. Diabetes significantly increased the expression of all the proteins in the rat aorta. Results are shown as mean \pm s.e.m. *Significantly different from control rats (Student’s unpaired t-test, $\mathrm{p}<0.05$ ). 


\section{REFERENCES}

Abboud K, Bassila JC, Ghali-Ghoul R, Sabra R (2009) Temporal changes in vascular reactivity in early diabetes mellitus in rats: role of changes in endothelial factors and in phosphodiesterase activity. Am J Physiol Heart Circ Physiol 297: H836-845

Adak S, Wang Q, Stuehr DJ (2000) Arginine conversion to nitroxide by tetrahydrobiopterin-free neuronal nitric-oxide synthase. Implications for mechanism. J Biol Chem 275: 33554-33561

Alencar JL, Chalupsky K, Sarr M, Schini-Kerth V, Vanin AF, Stoclet J-C, Muller B (2003) Inhibition of arterial contraction by dinitrosyl-iron complexes: critical role of the thiol ligand in determining rate of nitric oxide (NO) release and formation of releasable NO stores by S-nitrosation. Biochem Pharmacol 66: 23652374

Alper G, Olukman M, rer S, Çalayan O, Duman E, Ylmaz C, Ülker S (2006) Effect of vitamin E and C supplementation combined with oral antidiabetic therapy on the endothelial dysfunction in the neonatally streptozotocin injected diabetic rat. Diab/Metabol Res and Rev 22: 190 - 197

Altan VM, Karasu C, Özüari A (1989) The effects of type-1 and type-2 diabetes on endothelium-dependent relaxation in rat aorta. Pharmacol Biochem Behav 33: 519-522

Ammar RF, Jr., Gutterman DD, Brooks LA, Dellsperger KC (2000) Free radicals mediate endothelial dysfunction of coronary arterioles in diabetes. Cardiovasc Res 47: 595-601

Bartnik M, Norhammar A, Ryden L (2007) Hyperglycaemia and cardiovascular disease. J Intern Med 262: $145-156$

Batenburg WW, Kappers MH, Eikmann MJ, Ramzan SN, de Vries R, Danser AH (2009) Light-induced vs. bradykinin-induced relaxation of coronary arteries: do S-nitrosothiols act as endothelium-derived hyperpolarizing factors? J Hypertens 27: 1631-1640

Bates JN, Harrison DG, Myers PR, Minor RL (1991) EDRF: nitrosylated compound or authentic nitric oxide. Basic Res Cardiol 86 Suppl 2: 17-26

Beckman JS, Crow JP (1993) Pathological implications of nitric oxide, superoxide and peroxynitrite formation. Biochem Soc Trans 21: 330-334

Bitar MS, Wahid S, Mustafa S, Al-Saleh E, Dhaunsi GS, Al-Mulla F (2005) Nitric oxide dynamics and endothelial dysfunction in type II model of genetic diabetes. Eur J Pharmacol 511: 53-64 
Bojunga J, Dresar-Mayert B, Usadel K-H, Kusterer K, Zeuzem S (2004) Antioxidative treatment reverses imbalances of nitric oxide synthase isoform expression and attenuates tissue-cGMP activation in diabetic rats. Biochem Biophys Res Comm 316: 771-780

Brahler S, Kaistha A, Schmidt VJ, Wolfle SE, Busch C, Kaistha BP, Kacik M, Hasenau AL, Grgic I, Si H, Bond CT, Adelman JP, Wulff H, de Wit C, Hoyer J, Kohler R (2009) Genetic deficit of SK3 and IK1 channels disrupts the endothelium-derived hyperpolarizing factor vasodilator pathway and causes hypertension. Circ 119: 2323-2332

Brondum E, Kold-Petersen H, Simonsen U, Aalkjaer C (2010) NS309 restores EDHF-type relaxation in mesenteric small arteries from type 2 diabetic ZDF rats. Br J Pharmacol 159: 154-165

Bryan RM, You J, Golding EM, Marrelli SP (2005) Endothelium-derived Hyperpolarizing Factor: A Cousin to Nitric Oxide and Prostacyclin. Anesthesiol 102: 1261-1277

Bullen ML, Miller AA, Dharmarajah J, Drummond GR, Sobey CG, Kemp-Harper BK (2011) Vasorelaxant and antiaggregatory actions of the nitroxyl donor isopropylamine NONOate are maintained in hypercholesterolemia. Am J Physiol Heart Circ Physiol 301: H1405-1414

Cameron JD, Cruickshank JK (2007) Glucose, insulin, diabetes and mechanisms of arterial dysfunction. Clin Exp Pharmacol Physiol 34: 677-682

Chan ECH, Drummond GR, Woodman OL (2003) 3', 4'-dihydroxyflavonol enhances nitric oxide bioavailability and improves vascular function after ischemia and reperfusion injury in the rat. J Cardiovas Pharmacol 42: 727-735

Clark SG, Fuchs LC (1997) Role of Nitric Oxide and $\mathrm{Ca}^{++}$-Dependent $\mathrm{K}^{+}$Channels in Mediating Heterogeneous Microvascular Responses to Acetylcholine in Different Vascular Beds. J Pharmacol Exp Ther 282: $1473-1479$

Csanyi G, Lepran I, Flesch T, Telegdy G, Szabo G, Mezei Z (2007) Lack of endothelium-derived hyperpolarizing factor (EDHF) up-regulation in endothelial dysfunction in aorta in diabetic rats. Pharmacol Rep 59: 447-455

Dalsgaard T, Kroigaard C, Misfeldt M, Bek T, Simonsen U (2010) Openers of small conductance calciumactivated potassium channels selectively enhance NO-mediated bradykinin vasodilatation in porcine retinal arterioles. Br J Pharmacol 160: 1496-1508 
Ding H, Hashem M, Triggle C (2007) Increased oxidative stress in the streptozotocin-induced diabetic apoEdeficient mouse: changes in expression of NADPH oxidase subunits and eNOS. Eur J Pharmacol 561: 121128

Ellis A, Triggle CR (2003) Endothelium-derived reactive oxygen species: their relationship to endotheliumdependent hyperpolarization and vascular tone. Can J Physiol Pharmacol 81: 1013-1028

Fang XD, Yang F, Zhu L, Shen YL, Wang LL, Chen YY (2009) Curcumin ameliorates high glucose-induced acute vascular endothelial dysfunction in rat thoracic aorta. Clin Exp Pharmacol Physiol 36: 1177-1182

Frank PG, Hassan GS, Rodriguez-Feo JA, Lisanti MP (2007) Caveolae and Caveolin-1: Novel Potential Targets for the Treatment of Cardiovascular Disease. Curr Pharma Design 13: 1761-1769

Garcia-Pascual A, Labadia A, Jimenez E, Costa G (1995) Endothelium-dependent relaxation to acetylcholine in bovine oviductal arteries: mediation by nitric oxide and changes in apamin-sensitive $\mathrm{K}^{+}$conductance. $\mathrm{Br} \mathrm{J}$ Pharmacol 115: 1221-1230

Garcia VMC, Ochoa JE, Elias MM (1999) Effect of early stage of experimental diabetes on vascular functions in isolated perfused kidneys. J Auton Pharmacol 19: 97-103

Goel A, Zhang Y, Anderson L, Rahimian R (2007) Gender difference in rat aorta vasodilation after acute exposure to high glucose: Involvement of protein kinase $\mathrm{C}\{$ beta $\}$ and superoxide but not of Rho Kinase. Cardiovasc Res 76: 351-360

Gomes MB, Affonso FS, Cailleaux S, Almeida AL, Pinto LF, Tibirica E (2004) Glucose levels observed in daily clinical practice induce endothelial dysfunction in the rabbit macro- and microcirculation. Fundam Clin Pharmacol 18: 339-346

Guo Z, Xia Z, Jiang J, McNeill JH (2007) Downregulation of NADPH oxidase, antioxidant enzymes, and inflammatory markers in the heart of streptozotocin-induced diabetic rats by N-acetyl-L-cysteine. Am J Physiol Heart Circ Physiol 292: H1728-1736

Hink U, Li H, Mollnau H, Oelze M, Matheis E, Hartmann M, Skatchkov M, Thaiss F, Stahl RAK, Warnholtz A, Meinertz T, Griendling K, Harrison DG, Forstermann U, Munzel T (2001) Mechanisms underlying endothelial dysfunction in diabetes mellitus. Circ Res 88: e14-22

Jay D, Hitomi H, Griendling KK (2006) Oxidative stress and diabetic cardiovascular complications. Free Rad Biol Med 40: 183-192 
Jesmin S, Zaedi S, Maeda S, Yamaguchi I, Goto K, Miyauchi T (2006) Effects of a Selective Endothelin A Receptor Antagonist on the Expressions of iNOS and eNOS in the Heart of Early Streptozotocin-Induced Diabetic Rats. Exp Biol Med 231: 925-931

Johnstone MT, Creager SJ, Scales KM, Cusco JA, Lee BK, Creager MA (1993) Impaired endotheliumdependent vasodilation in patients with insulin-dependent diabetes mellitus. Circ 88: 2510-2516

Karasu Ç (2000) Time course of changes in endothelium-dependent and -independent relaxation of chronically diabetic aorta: role of reactive oxygen species. Eur J Pharmacol 392: 163-173

Kim-Shapiro DB, Schechter AN, Gladwin MT (2006) Unraveling the reactions of nitric oxide, nitrite, and hemoglobin in physiology and therapeutics. Arterioscler Thromb Vasc Biol 26: 697-705

Komers R, Schutzer WE, Reed JF, Lindsley JN, Oyama TT, Buck DC, Mader SL, Anderson S (2006) Altered endothelial nitric oxide synthase targeting and conformation and caveolin-1 expression in the diabetic kidney. Diab 55: 1651-1659

Lima B, Forrester MT, Hess DT, Stamler JS (2010) S-nitrosylation in cardiovascular signaling. Circ Res 106: $633-646$

Lopes-Virella MF, Carter RE, Gilbert GE, Klein RL, Jaffa M, Jenkins AJ, Lyons TJ, Garvey WT, Virella G (2008) Risk factors related to inflammation and endothelial dysfunction in the DCCT/EDIC cohort and their relationship with nephropathy and macrovascular complications. Diab Care 31: 2006-2012

Malakul W, Thirawarapan S, Suvitayavat W, Woodman OL (2008) Type 1 diabetes and hypercholesterolaemia reveal the contribution of endothelium-derived hyperpolarizing factor to endotheliumdependent relaxation of the rat aorta. Clin Exp Pharmacol Physiol 35: 192-200

Myers PR, Minor RL, Jr., Guerra R, Jr., Bates JN, Harrison DG (1990) Vasorelaxant properties of the endothelium-derived relaxing factor more closely resemble S-nitrosocysteine than nitric oxide. Nature 345: $161-163$

Nacci C, Tarquinio M, De Benedictis L, Mauro A, Zigrino A, Carratu MR, Quon MJ, Montagnani M (2009) Endothelial Dysfunction in Mice with Streptozotocin-induced Type 1 Diabetes Is Opposed by Compensatory Overexpression of Cyclooxygenase-2 in the Vasculature. Endocrinol 150: 849-861

Ng ESM, Cheng Z-J, Ellis A, Ding H, Jiang Y, Li Y, Hollenberg MD, Triggle CR (2007) Nitrosothiol stores in vascular tissue: Modulation by ultraviolet light, acetylcholine and ionomycin. Eur J Pharmacol 560: 183192 
Orie NN, Aloamaka CP, Iyawe VI (1993) Duration-dependent attenuation of acetylcholine--but not histamine--induced relaxation of the aorta in diabetes mellitus. Gen Pharmacol 24: 329-332

Oyama Y, Kawasaki H, Hattori Y, Kanno M (1986) Attenuation of endothelium-dependent relaxation in aorta from diabetic rats. Eur J Pharmacol 132: 75-78

Peredo HA, Rodríguez R, Susemihl MC, Villarreal I, Filinger E (2006) Long-term streptozotocin-induced diabetes alters prostanoid production in rat aorta and mesenteric bed. Autonom Autacoid Pharmacol 26: 355360

Pieper GM (1999) Enhanced, unaltered and impaired nitric oxide-mediated endothelium-dependent relaxation in experimental diabetes mellitus: importance of disease duration. Diabetol 42: 204-213

Pieper GM, Dembny K, Siebeneich W (1998) Long-term treatment in vivo with NOX-101, a scavenger of nitric oxide, prevents diabetes-induced endothelial dysfunction. Diabetol 41: 1220-1226

Riad A, Westermann D, Van Linthout S, Mohr Z, Uyulmaz S, Becher PM, Rutten H, Wohlfart P, Peters H, Schultheiss HP, Tschope C (2008) Enhancement of endothelial nitric oxide synthase production reverses vascular dysfunction and inflammation in the hindlimbs of a rat model of diabetes. Diabetol 51: 2325-2332 Rusche KM, Spiering MM, Marletta MA (1998) Reactions catalyzed by tetrahydrobiopterin-free nitric oxide synthase. Biochemistry 37: 15503-15512

Satoh M, Fujimoto S, Haruna Y, Arakawa S, Horike H, Komai N, Sasaki T, Tsujioka K, Makino H, Kashihara N (2005) NAD(P)H oxidase and uncoupled nitric oxide synthase are major sources of glomerular superoxide in rats with experimental diabetic nephropathy. Am J Physiol Renal Physiol 288: F1144-1152

Shen B, Ye C-L, Ye K-H, Liu J-J, Sun P, Jiang J-H (2003) Mechanism underlying enhanced endotheliumdependent vasodilatation in thoracic aorta of early stage streptozotocin-induced diabetic mice. Acta Pharmacol Sin 24: 422-428

Sheng J-Z, Braun AP (2007) Small- and intermediate-conductance $\mathrm{Ca}^{2+}$-activated $\mathrm{K}^{+}$channels directly control agonist-evoked nitric oxide synthesis in human vascular endothelial cells. Am J Physiol Cell Physiol 293: C458-467

Sheng JZ, Ella S, Davis MJ, Hill MA, Braun AP (2009) Openers of SKCa and IKCa channels enhance agonist-evoked endothelial nitric oxide synthesis and arteriolar vasodilation. Faseb J 23: 1138-1145 
Shi Y, Ku DD, Man RYK, Vanhoutte PM (2006) Augmented endothelium-derived hyperpolarizing factormediated relaxations attenuate endothelial dysfunction in femoral and mesenteric, but not in carotid arteries from type I diabetic rats. J Pharmacol Exp Ther 318: 276-281

Sobey CG, Weiler JM, Boujaoude M, Woodman OL (2004) Effect of short-term phytoestrogen treatment in male rats on nitric oxide-mediated responses of carotid and cerebral arteries: comparison with 17betaestradiol. J Pharmacol Exp Ther 310: 135-140

Stadler K, Jenei V, von Bolcshazy G, Somogyi A, Jakus J (2003) Increased nitric oxide levels as an early sign of premature aging in diabetes. Free Rad Biol Med 35: 1240-1251

Stankevicius E, Dalsgaard T, Kroigaard C, Beck L, Boedtkjer E, Misfeldt MW, Nielsen G, Schjorring O, Hughes A, Simonsen U (2011) Opening of small and intermediate calcium-activated potassium channels induces relaxation mainly mediated by nitric-oxide release in large arteries and endothelium-derived hyperpolarizing factor in small arteries from rat. J Pharmacol Exp Ther 339: 842-850

Stankevicius E, Lopez-Valverde V, Rivera L, Hughes AD, Mulvany MJ, Simonsen U (2006) Combination of $\mathrm{Ca}^{2+}$-activated $\mathrm{K}^{+}$channel blockers inhibits acetylcholine-evoked nitric oxide release in rat superior mesenteric artery. Br J Pharmacol 149: 560-572

Stockklauser-Färber K, Ballhausen T, Laufer A, Rösen P (2000) Influence of diabetes on cardiac nitric oxide synthase expression and activity. Biochimica et Biophysica Acta (BBA) - Molecular Basis of Disease 1535: $10-20$

Takahashi S, Mendelsohn ME (2003) Calmodulin-dependent and -independent activation of endothelial nitric-oxide synthase by heat shock protein 90. J Biol Chem 278: 9339-9344

Vera R, Sanchez M, Galisteo M, Villar IC, Jimenez R, Zarzuelo A, Perez-Vizcaino F, Duarte J (2007) Chronic administration of genistein improves endothelial dysfunction in spontaneously hypertensive rats: involvement of eNOS, caveolin and calmodulin expression and NADPH oxidase activity. Clin Sci (Lond) 112: $183-191$

Wendt MC, Daiber A, Kleschyov AL, Mulsch A, Sydow K, Schulz E, Chen K, Keaney JJF, Lassegue B, Walter U, Griendling KK, Munzel T (2005) Differential effects of diabetes on the expression of the gp91phox homologues nox1 and nox4. Free Radic Biol Med 39: 381-391 
Woodman OL, Missen MA, Boujaoude M (2004) Daidzein and 17 beta-estradiol enhance nitric oxide synthase activity associated with an increase in calmodulin and a decrease in caveolin-1. J Cardiovasc Pharmacol 44: 155-163

Yuill KH, Yarova P, Kemp-Harper BK, Garland CJ, Dora KA (2011) A novel role for HNO in local and spreading vasodilatation in rat mesenteric resistance arteries. Antioxid Redox Signal 14: 1625-1635 
Table1: Initial and final body weights, blood glucose, superoxide counts from aortic rings and plasma nitrite levels in control and diabetic animals.

\begin{tabular}{lcc}
\hline & Control & Diabetic \\
\hline Initial body weight $(\mathrm{g})$ & $268 \pm 13$ & $245 \pm 8$ \\
Final body weight $(\mathrm{g})$ & $451 \pm 7$ & $306 \pm 14^{*}$ \\
Blood glucose (mmol/L) & $9.8 \pm 1$ & $>33^{*}$ \\
Superoxide counts (AU/mg dry & $986 \pm 163$ & $2180 \pm 363^{*}$ \\
tissue weight) & & $177 \pm 53$ \\
$\begin{array}{l}\text { Superoxide counts in the } \\
\text { presence of DPI (AU/mg dry }\end{array}$ & $112 \pm 18$ & \\
tissue weight) & & $272 \pm 68^{*}$ \\
Plasma nitrite levels ( $\mu \mathrm{mol} / \mathrm{L})$ & $114 \pm 16$ &
\end{tabular}

The data is expressed as mean \pm SEM.

*Significantly different from control group (Student's unpaired t-test, $\mathrm{p}<0.05$ ). 
Table 2: Parameters for endothelium-dependent and independent relaxation in response to ACh and SNP in aortic rings from control and diabetic rats. The effects of L-NNA (100 $\mu \mathrm{M})$, ODQ $(10 \mu \mathrm{M})$ and indomethacin (Indo, $10 \mu \mathrm{M}$ ) on responses to ACh and SNP are shown.

\begin{tabular}{lcccccc}
\hline & \multicolumn{3}{c}{ Control } & \multicolumn{3}{c}{ Diabetic } \\
\hline ACh & $\mathbf{n}$ & $\mathbf{p E C}_{\mathbf{5 0}}$ & $\mathbf{R}_{\mathbf{m a x}}$ & $\mathbf{n}$ & $\mathbf{p E C}_{\mathbf{5 0}}$ & $\mathbf{R}_{\max }$ \\
\hline Vehicle & 7 & $7.36 \pm 0.1$ & $92 \pm 4$ & 7 & $7.34 \pm 0.11$ & $88 \pm 5$ \\
L-NNA & 7 & $\mathrm{ND}$ & $10 \pm 6^{*}$ & 7 & $6.78 \pm 0.1^{*}$ & $54 \pm 7^{* \#}$ \\
ODQ & 7 & $\mathrm{ND}$ & $6 \pm 4^{*}$ & 7 & $6.77 \pm 0.15^{*}$ & $46 \pm 13^{*}$ \\
Indo & 7 & $7.43 \pm 0.1$ & $91 \pm 4$ & 7 & $7.48 \pm 0.12$ & $93 \pm 2$ \\
\hline SNP & & & & & & \\
\hline Vehicle & 7 & $8.13 \pm 0.14$ & $100 \pm 0$ & 7 & $8.57 \pm 0.27$ & $101 \pm 2$ \\
L-NNA & 7 & $8.74 \pm 0.24^{*}$ & $101 \pm 1$ & 7 & $9.35 \pm 0.16^{* \#}$ & $101 \pm 2$ \\
ODQ & 7 & $5.80 \pm 0.34^{*}$ & $50 \pm 11^{*}$ & 7 & $6.54 \pm 0.0 *^{*}$ & $55 \pm 6^{*}$ \\
Indo & 7 & $8.10 \pm 0.19$ & $95 \pm 4$ & 7 & $8.59 \pm 0.15$ & $101 \pm 2$ \\
\hline
\end{tabular}

The data is expressed as mean \pm SEM.

$\mathrm{n}=$ number of experiments

$\mathrm{ND}=$ not determined

* Significantly different compared to vehicle in the same treatment group (one way ANOVA, Bonferroni post test, $\mathrm{p}<0.05)$.

\#Significantly different compared to the control group (Student's unpaired t-test, $\mathrm{p}<0.05$ ). 
Table 3: The effect of various treatments on responsed to ACh and SNP in aortic rings from control and diabetic rats. All the experiments were performed in the presence of indomethacin. The combination of apamin+TRAM-34 had no effect on relaxation in any of the group. ODQ+L-NNA+ apamin +TRAM-34 treatment completely abolished relaxation in both the groups. Responses to ACh in the diabetic group showed a resistance to inhibition by L-NNA+ODQ, but were abolished by additional presence of $\mathrm{Hb}$.

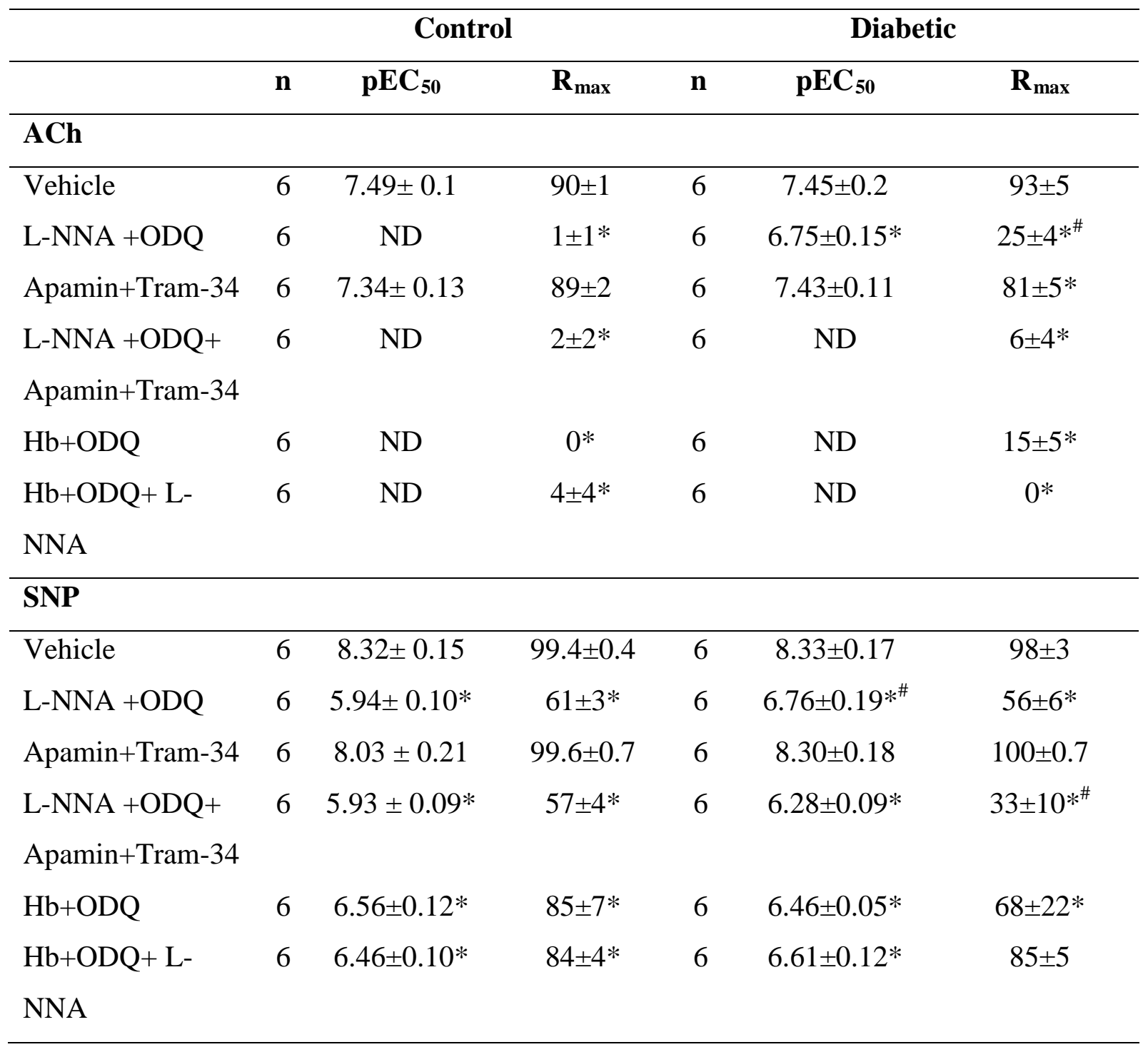

The data is expressed as mean \pm SEM. $n=$ number of experiments

$\mathrm{ND}=$ not determined

* Significantly different compared to vehicle in the same treatment group (one way ANOVA, Bonferroni post test, $\mathrm{p}<0.05)$. \# Significantly different compared to the same treatment group from the control animals (Student's unpaired t-test, $\mathrm{p}<0.05$ ). 
Table 4: The effect of the NO scavenger carboxy-PTIO and L-cysteine on $\mathrm{pEC}_{50}$ and $\mathrm{R}_{\max }$ in aortic rings from diabetic rats for ACh concentration response curve. All these experiments were performed in the presence of indomethacin.

\begin{tabular}{lccc}
\hline \multicolumn{1}{c}{ Treatment } & \multicolumn{2}{c}{ Diabetic } \\
& $\mathbf{n}$ & pEC $_{50}$ & $\mathbf{R}_{\max }$ \\
\hline ACh & & & \\
\hline Vehicle & 7 & $7.19 \pm 0.08$ & $93 \pm 3$ \\
L-NNA & 7 & $6.69 \pm 0.14^{*}$ & $44 \pm 6^{*}$ \\
L-NNA+PTIO & 6 & $6.33 \pm 0.06^{*}$ & $26 \pm 4^{*}$ \\
L-NNA +L-cys & 5 & $6.23 \pm 0.23^{*}$ & $15 \pm 6^{* \#}$ \\
\hline
\end{tabular}

The data is expressed as mean \pm SEM. $n=$ number of experiments

* Significantly different compared to vehicle (one way ANOVA, Bonferroni post test, $\mathrm{p}<0.05$ ).

\# Significantly different compared to L-NNA (one way ANOVA, Bonferroni post test, $\mathrm{p}<0.05$ ). 
Figure 1

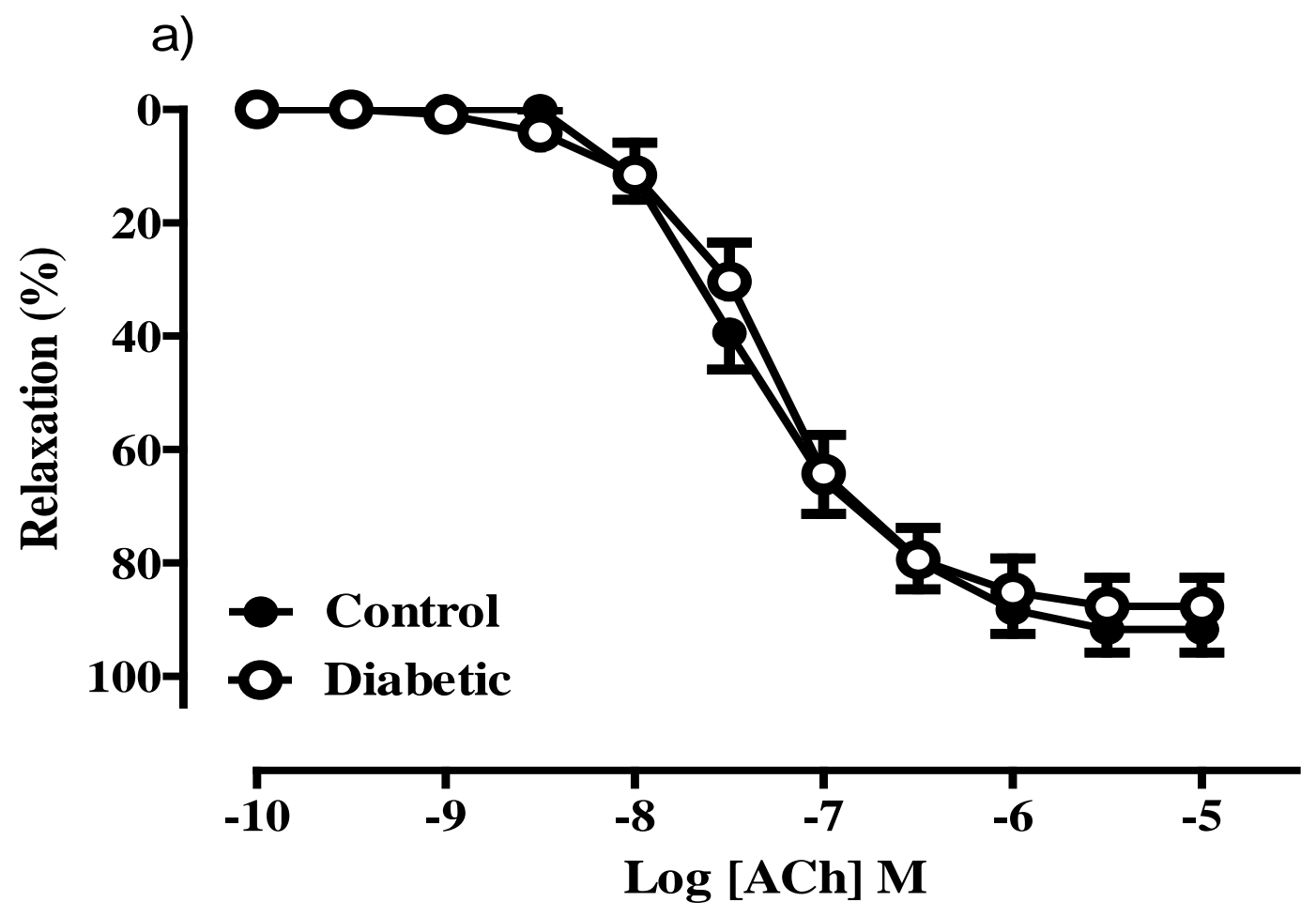

b)

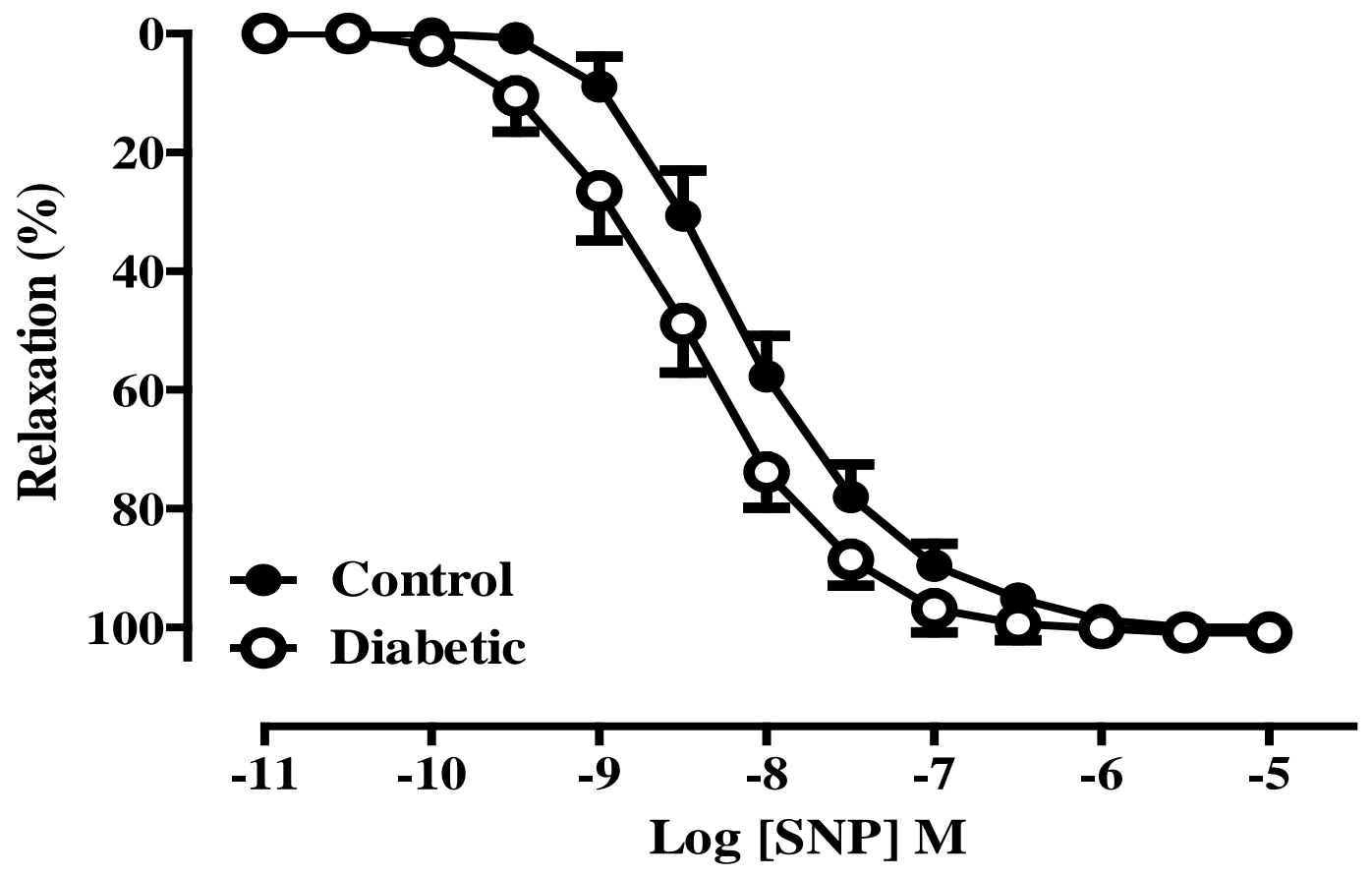



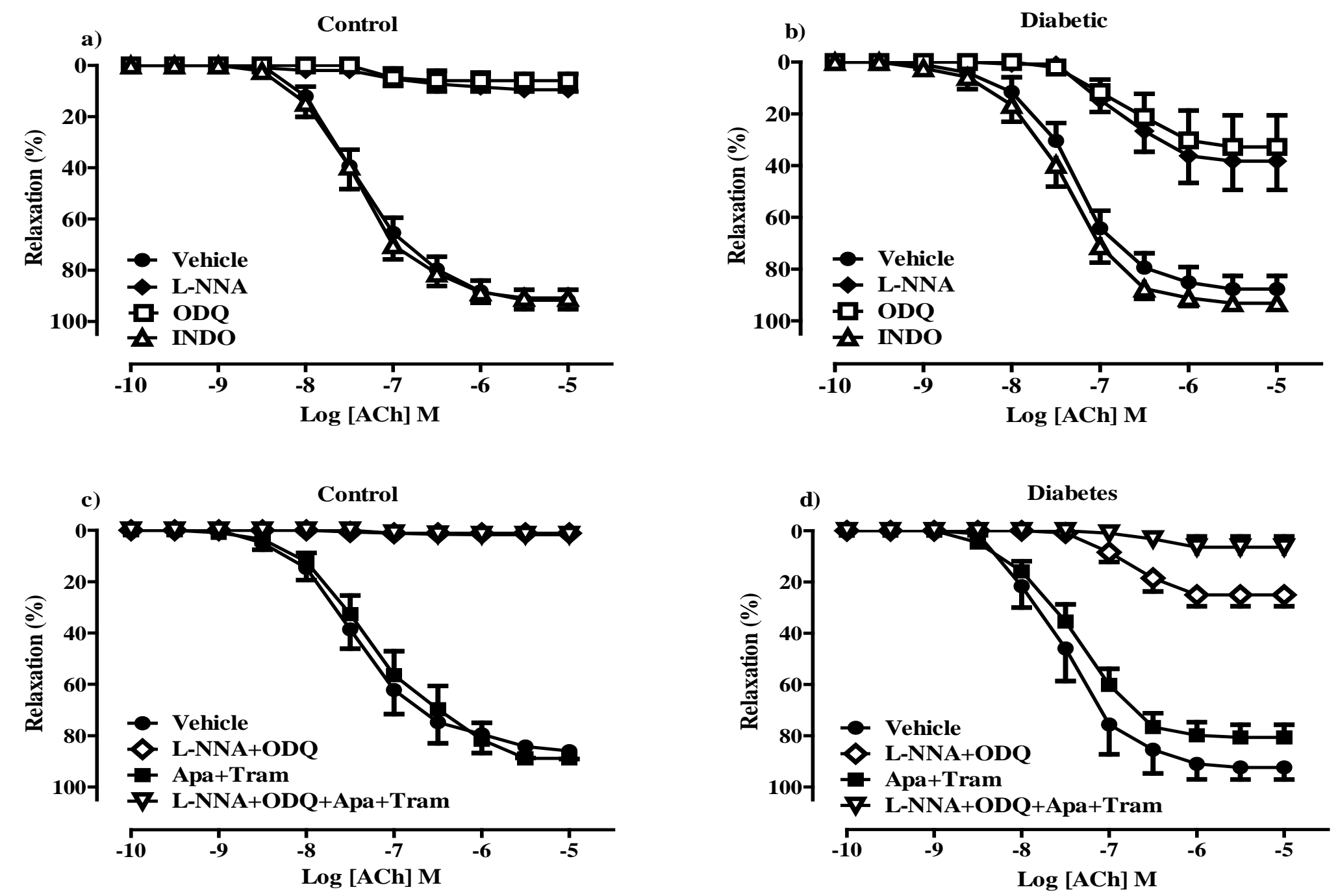
Figure 3
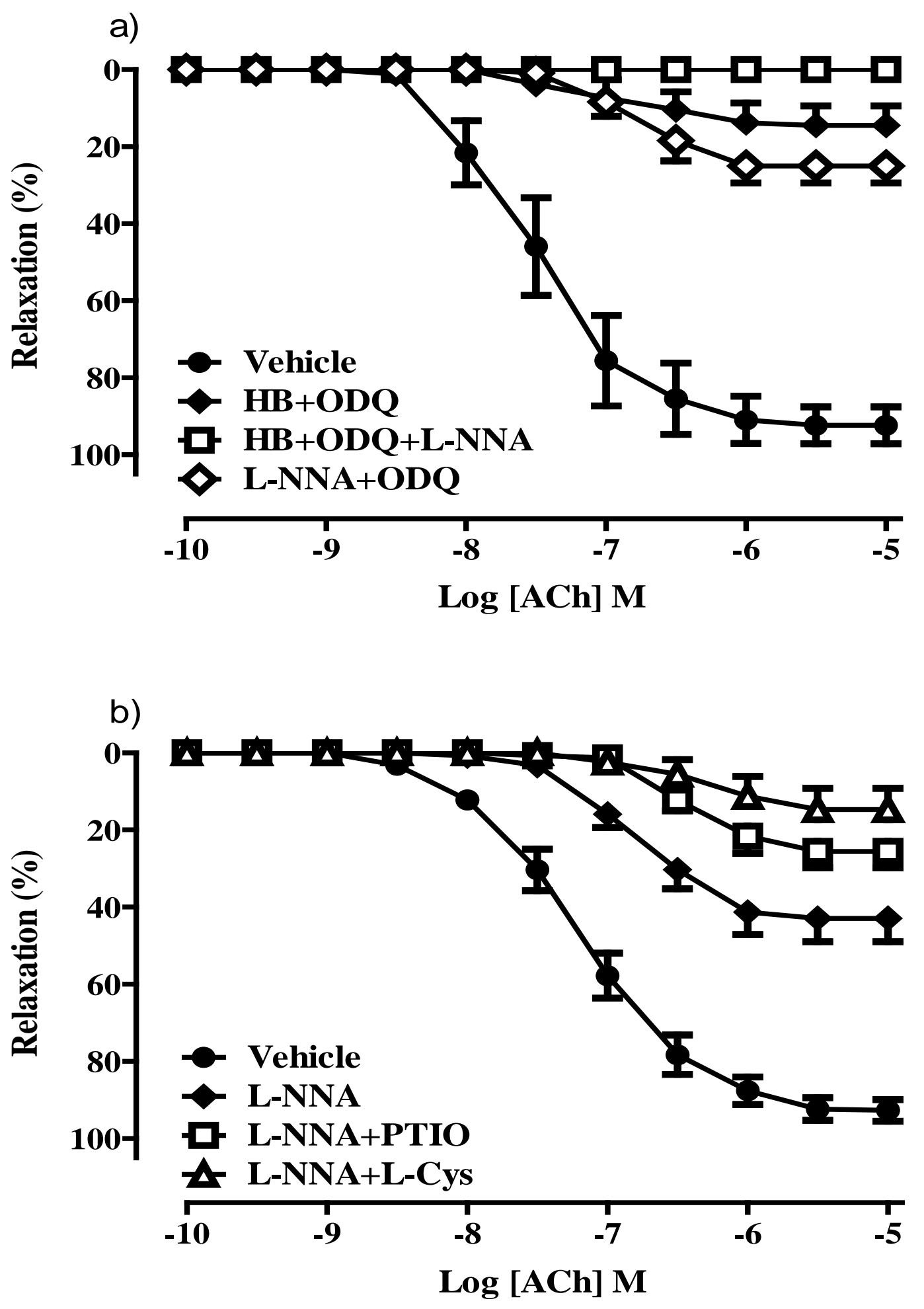
Figure 4

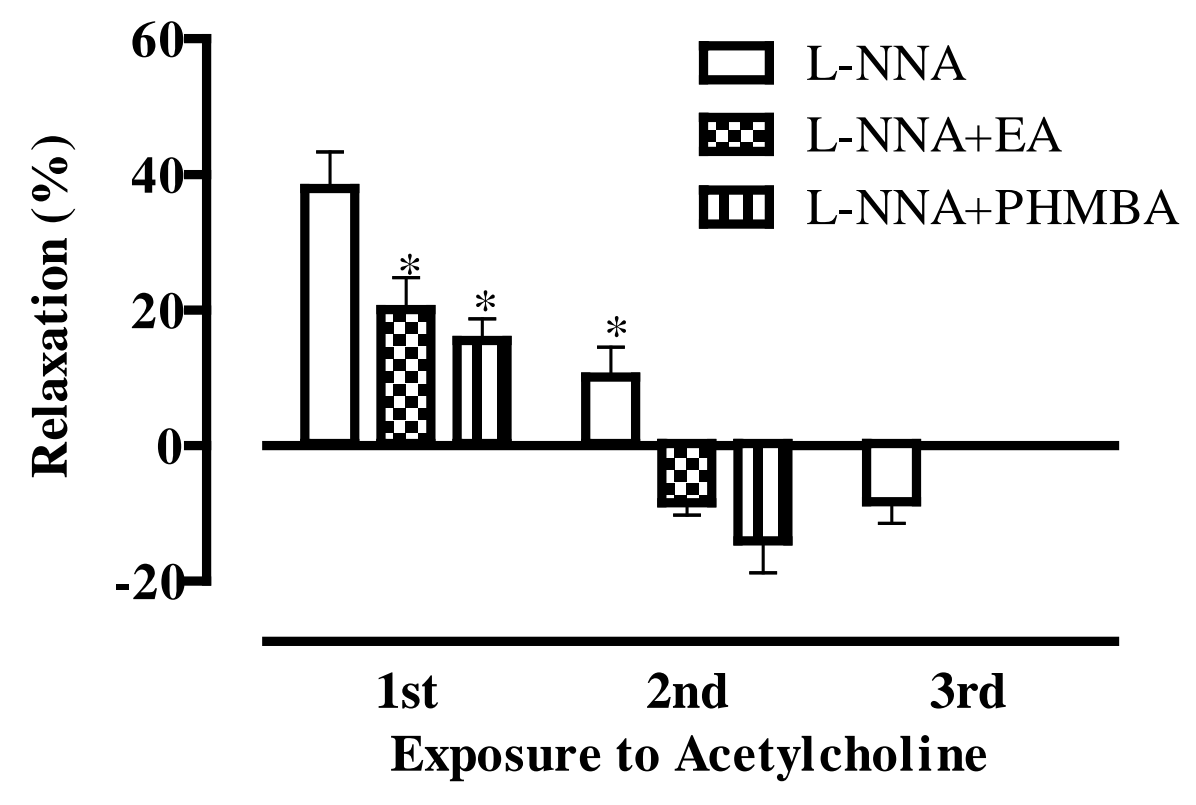




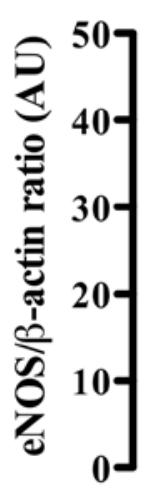
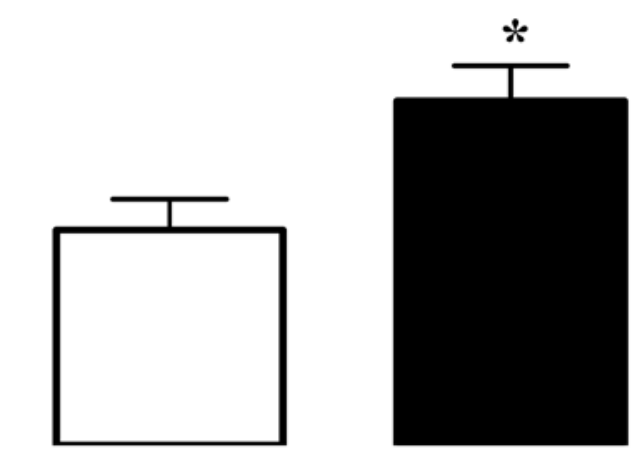

Control

Diabetic

eNOS (130 KDa)

$\beta$-actin (42kDa)
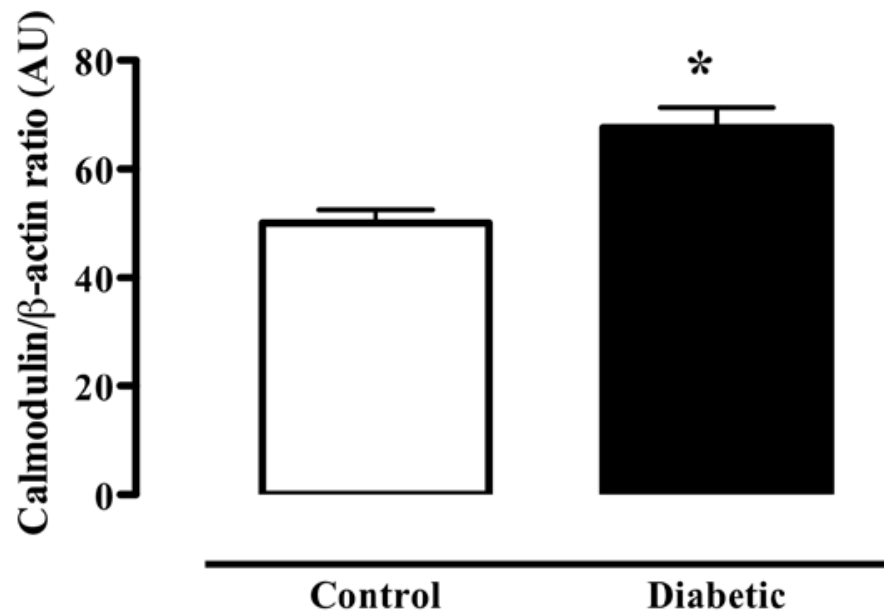

Calmodulin (17kDa)

$\beta$-actin (42kDa)

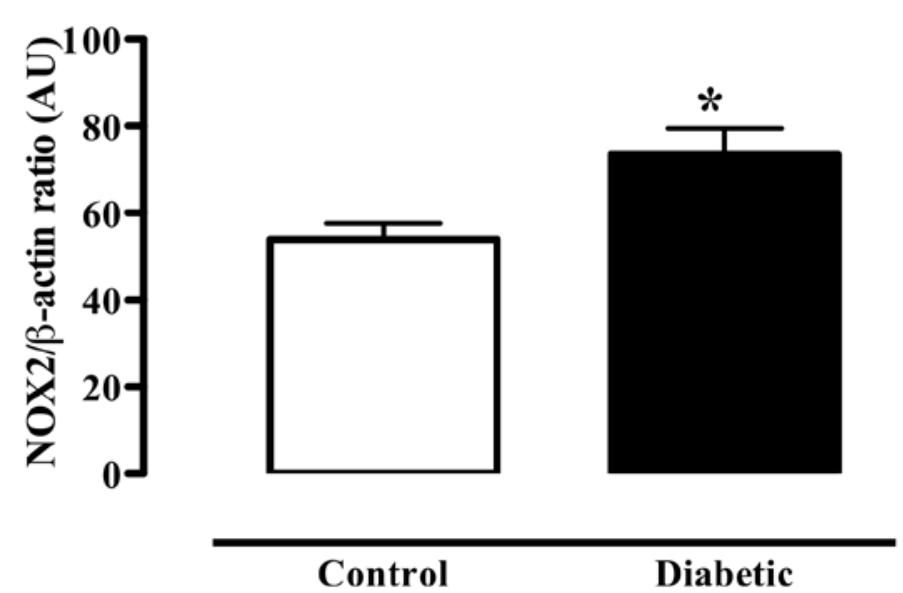

NOX2 (65 kDa)

$\beta$-actin (42kDa)

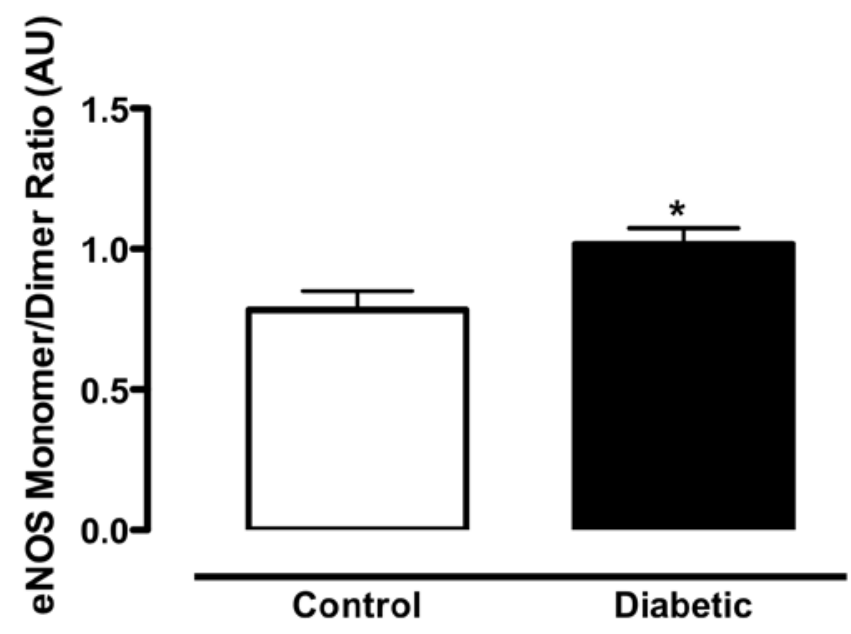

eNOS dimer

eNOS monomer 